\title{
Landslides triggered by the 2015 Gorkha Earthquake and analysis of their long-lasting impact
}

\author{
*Hikaru Tomita1, Alessandra Mayumi Nakata², Kazuo Konagai², Takashi Matsushima², \\ Masataka Shiga1, Takaaki Ikeda4, and Rama Mohan Pokhrel5 \\ ${ }^{1}$ Graduate school of Urban Innovation, Yokohama National University, Yokohama, Japan \\ 2Institute of Urban Innovation, Yokohama National University, Yokohama, Japan \\ ${ }^{3}$ Division of Engineering Mechanics and Energy, University of Tsukuba, Ibaraki, Japan \\ ${ }^{4}$ Dept., Civil and environmental Eng., Nagaoka University of Technology, Niigata, Japan \\ ${ }^{5}$ Earth Investigation and Solution Nepal Pvt. Ltd., Kathmandu, Nepal \\ *Corresponding author: tomita-hikaru-vg@ynu.jp
}

\begin{abstract}
The Gorkha earthquake of April 25, 2015 has caused many landslides along the Trishuli River in the Rasuwa District. A numerical approach has been taken to assess the remaining risk of landslides. The debris mass movements are described in simulations with only three parameters, namely, the critical angle if, Gauckler-Manning roughness coefficient $\mathrm{n}$, and angle of repose id. The optimum set of these three parameters, obtained through a batch of numerical simulations to minimize the prediction error, was then used to identify locations of unstable colluvium deposits remaining along gullies on steep valley walls of the Trishuli River.
\end{abstract}

Keywords: Landslides risk assessment, Gorkha earthquake, Depth-integrated particle method

Paper Received: 31 Jan 2018

Paper Accepted: 8 March 2018

\section{INTRODUCTION}

The 2015 Nepal Earthquake $(\mathrm{Mw}=7.8)$, also called the Gorkha Earthquake, was the worst natural disaster to hit Nepal since the 1934 Nepal-Bihar earthquake. The earthquake had triggered almost 19,000 slope failures (Gnyawali and Adhikari, 2017). Not only had the landslides taken the lives of so many people, but they had also given a big impact on infrastructures. 18 existing hydropower plants were stopped due to the earthquake and subsequent landslides, resulting in an outage of $171 \mathrm{MW}$ (Government of Nepal National Planning Commission, 2015). Furthermore, unstable rock masses still sitting atop of exposed bare slopes will cause long lasting problems. The Trishuli 3A hydropower plant located in the Rasuwa District was under construction when the Gorkha Earthquake hit. Its construction was intermittently interrupted by the subsequent landslides and its completion were delayed for 34 months. This paper attempts to assess the remaining risk of slope failures through numerical simulations and field surveys, focusing on areas along Trishuli River in Rasuwa district, the district hardest hit by this earthquake.

The study area covers an about $10 \mathrm{~km}$ stretch of steep valley walls of the Trishuli River, which runs from northeast to southwest between Dhunche and Ramche in the Rasuwa District, about $70 \mathrm{~km}$ northwest of Kathmandu (Fig. 1). The Trishuli 3A Hydropower plant is currently under construction at the very center of the study area. About halfway or a little higher up the left valley wall of the Trishuli River, the Pasang Lhamu Highway goes windingly through the upper flank of mountains in the study area. Given the obstruction to the Araniko Highway, which had been the nation's vital road going through a large section of the quake-ravaged mountains, only the Pasang Lhamu Highway is now connecting Kathumandu and China.

\section{METHODOLOGY}

With thousands of landslides triggered by the Gorkha Earthquake, a straightforward approach to analyze every detail of slope movement is unrealistic for seeing the whole picture of the risk. Therefore, Depth Integrated Particle Method (DIPM) proposed by Nakata and Matsushima (2014) was used herein. DIPM traces initiating, sliding and depositing processes of landslide mass with only three corresponding parameters. Through a batch of simulations, the optimum set of parameters that minimize the error in estimating areas affected by landslides was nominated. The set of parameters reflecting the overall regional nature could be used for risk assessments of remaining unstable soil masses in the same and/or similar mountainous regions. The simulation consisted of the following two main steps.

\section{Step 1: Preparation of Digital Surface Model}

In the simulations, a Digital Surface Model (DSM) representing the surface of the terrain before the earthquake was needed. Authors used 'AW3D' global DSM provided by Remote Sensing Technology Center of Japan. This DSM was 


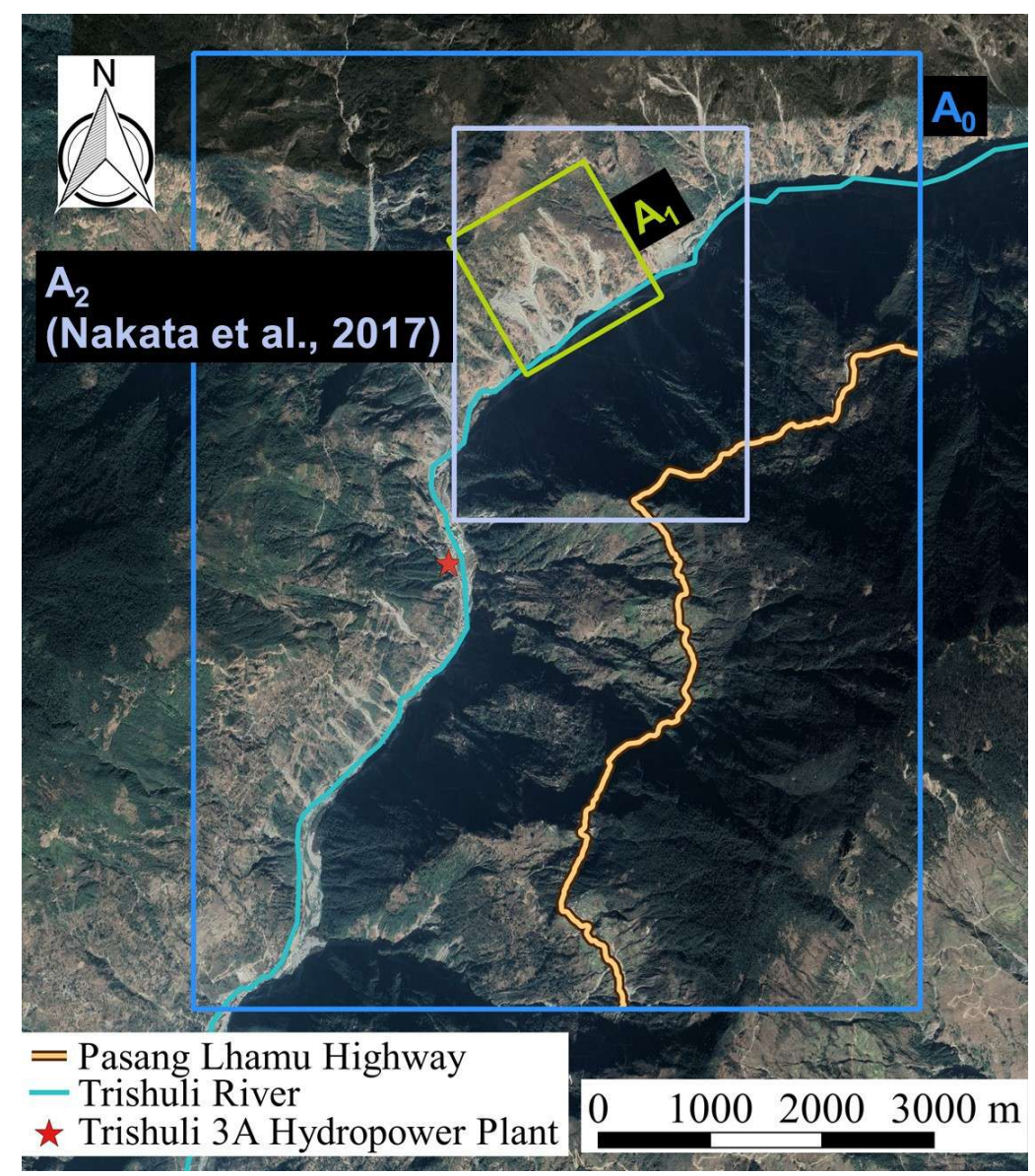

Fig. 1: Study area

created using images from PRISM sensor built in ALOS satellite (Tadono.et al., 2014). The spatial resolution of this DSM was $5 \mathrm{~m}$ by $5 \mathrm{~m}$.

\section{Step 2: Flow simulations}

In DIPM, it was assumed that the target area was uniformly covered up with debris mass with the same unit thickness and the same mechanical properties over its entire stretch. Under these assumptions, the model traces initiating, sliding and depositing processes of landslide mass with only three corresponding parameters: the critical angle $i_{f}$, Gauckler-Manning roughness coefficient $n$, and angle of repose $i_{d}$.

When the slope was steeper than the critical angle, $i_{f}$, the surface debris mass started sliding under its own weight. When the debris mass was in motion, flowing mass follows the shallow water equation, and the Gauckler-Manning roughness coefficient, $n$, affected its velocity. Once the mass reached its depositional area, the mass decelerated and oozed out until the periphery of the mass reached its angle of repose, $i_{d}$.

A sliding debris mass was described as an assemblage of soil columns arranged together over a sliding surface. The affected area in the DIPM simulation, , was the area where DIPM particles (columns) exhibit any movement. Every combination of the specified three parameter values could yield different value of the affected area. The affected area in each simulation was compared with the real value of the affected area, , observed from satellites, etc., and the optimum set of the three parameters, $i_{f}, n$, and $i_{d}$ were determined running a batch of simulations to maximize the likelihood of simulation, which is given by:

$$
L=\frac{A_{s} \cap A_{a}}{A_{s} \cup A_{a}}
$$

The optimum set of parameters can be used for risk assessments of remaining unstable soil masses in the similar mountainous regions

\section{FIELD SURVEYS}

Google Earth allows us to see how satellite images have changed over time, thus enabling us to detect locations and 


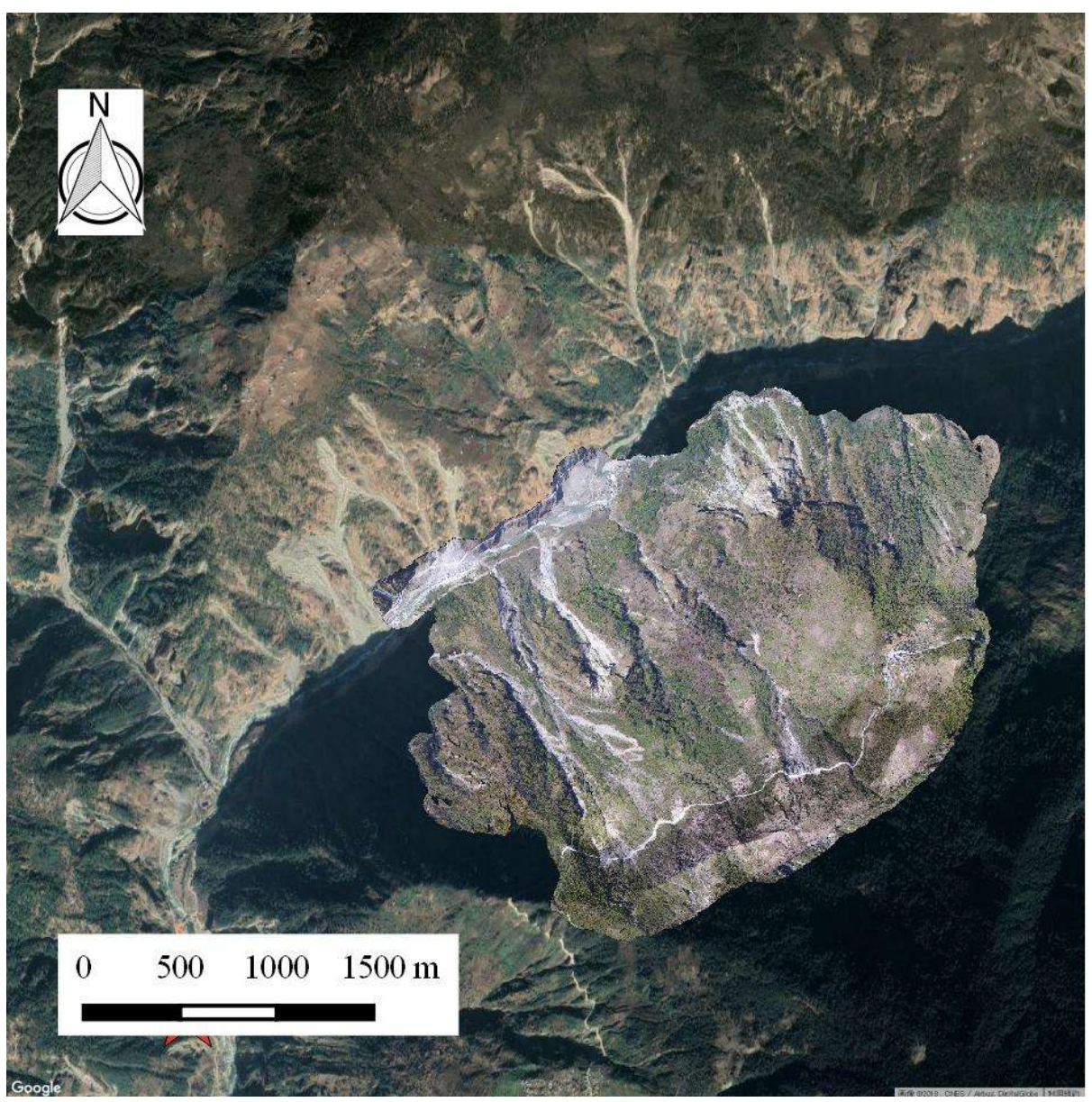

Fig. 2: UAV-photo-based ortho-image of southeastern valley wall of the Trishuli River laid upon Google Earth image ( $A_{2}$ in Fig. 1).

actual areas of earthquake-induced landslides as exposed bare earth with the vegetative canopy all wiped off. However, in a highly ragged mountainous terrain, deep valley walls facing north can often be shaded. Particularly, the greater part of the left valley wall of the Trishuli River is very difficult to see. To get clearer images, UAV (Unmanned aerial vehicle) flight was carried out on August 10, 2016 and April 9, 2017, to get both the post-earthquake digital surface model and the ortho-photo image of the terrain (Fig. 2).

\section{NUMERICAL SIMULATIONS AND DISCUSSIONS}

Optimum set of the parameters for a particular slope can differ depending on how far out we analyze. Within the DSMcovered study area $\left(A_{0}\right)$, a small left-leaning square computational area of $A_{l}$ is first taken to cover some of sharply defined gullies newly exposed on the northwestern valley wall. Encircling this area, one-size larger area $A_{2}$ (Nakata et al., 2017) is drawn to include the southeastern valley wall (Fig. 1). For each area, three parameters, $i_{f}, n$, and $i_{d}$, are varied over the ranges, 35 to 45 degrees, 0.1 to $0.3 \mathrm{~m}^{1 / 3} \mathrm{~s}$ and 10 to 30 degrees, respectively, to maximize the likelihood defined by Equation (1), and the optimum sets of parameters are determined to be:

$$
\begin{aligned}
i_{f} & =40^{0} \\
n & =0.10 \mathrm{~m}^{1 / 3} \mathrm{~S} \\
i_{d} & =30^{0}
\end{aligned}
$$

(for area $A_{1}$ with maximum likelihood of $L=34.4 \%$ reached)

and

$$
\begin{aligned}
& i_{f}=40^{0} \\
& n=0.15 \mathrm{~m}^{1 / 3} \mathrm{~S} \\
& i_{d}=25^{0}
\end{aligned}
$$

(for area $A_{2}$ with maximum likelihood of $L=26.0 \%$ reached)

The result indicates that only the critical angle, $i_{f}$, is less sensitive to the extent of the target area, while the others are highly dependent on it. This is because area, covering only the northwest valley wall, does not allow us to calculate the forces exerted by debris masses from the opposite southeast river wall, thus making both Gauckler-Manning roughness coefficient, $n$, and the angle of repose, $i_{d}$, larger than what they should be. 


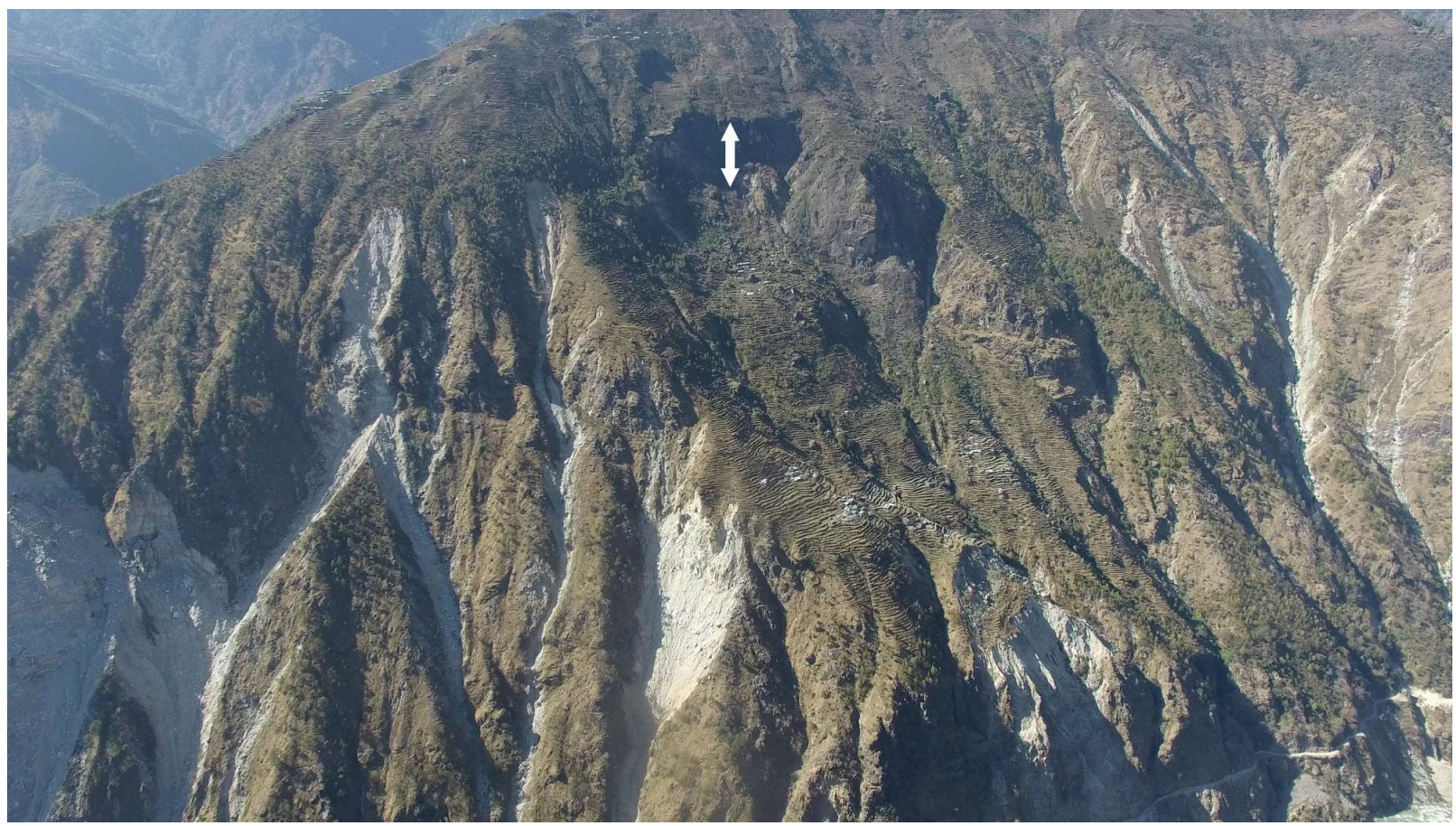

Fig. 3: Possible trace of past landslide

Though it is desirable to cover wider area for debris flow simulations, the maximum likelihood of $L=26.0 \%$ reached for area $A_{2}$ warrants further discussion. The remaining $74 \%$ may include past landslide traces as well as seemingly intact but presumably unstable debris masses. Therefore, an up-close look at the remaining $74 \%$ slopes is inevitable.

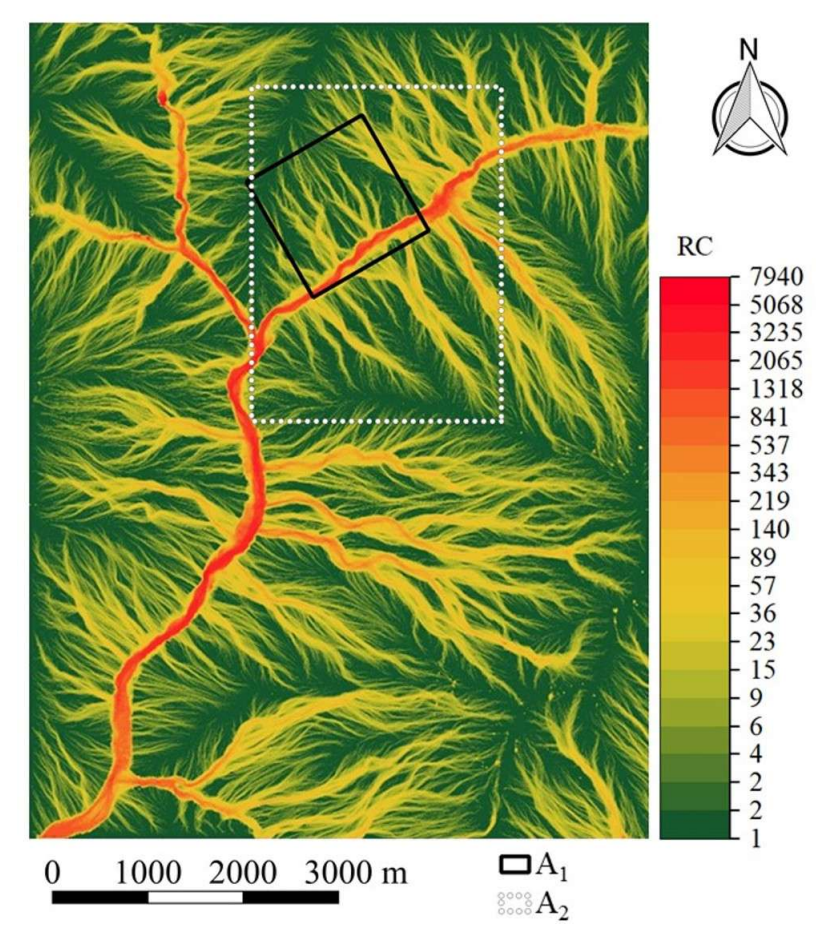

Fig. 4: RC value distribution over the whole target

area, $A_{0}$
Immediately above the exposed scars that appeared on the northwestern valley wall in the calculation area $A_{2}$, there is a vegetation-covered bowl-shaped depression as can be seen in Fig. 3. This depression has the look of a trace of a past landslide with a sheer rocky cliff as its top scar. A close-up image of this cliff (from our UAV flight in April 2017) shows fresh deposits

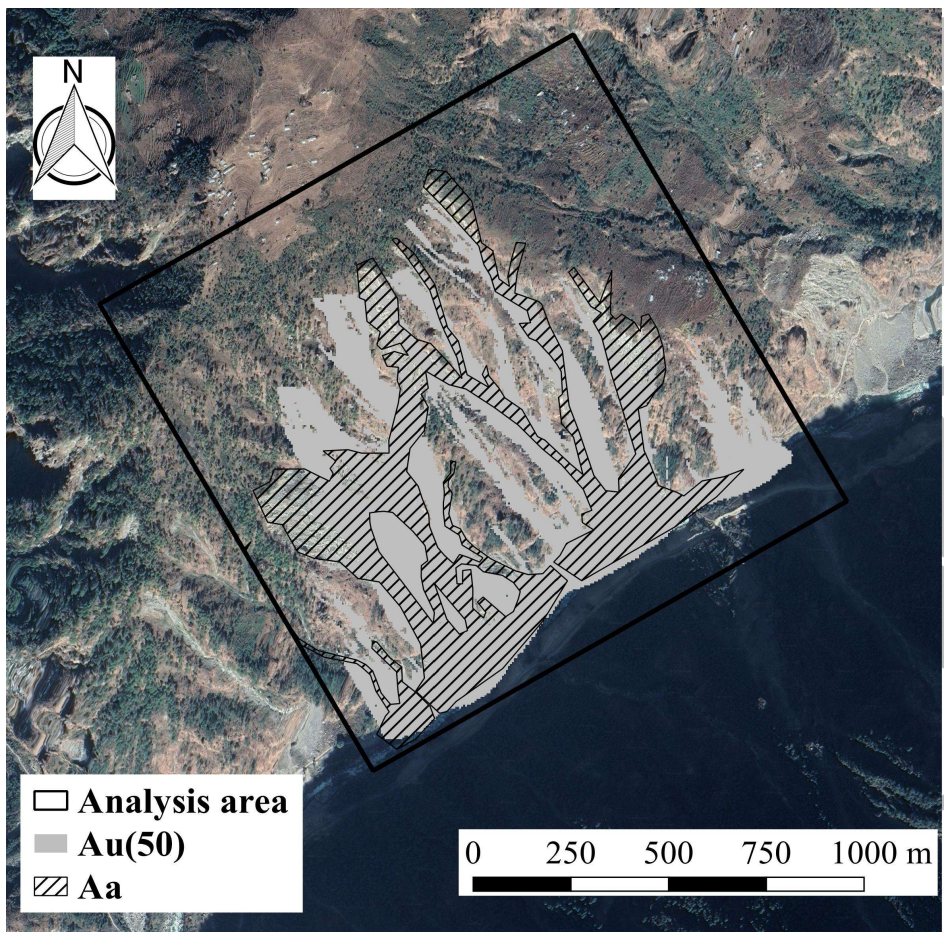

Fig. 5: Affected area $A_{u}(50)$ with $\mathrm{RC}>50$ 
of rock fragments at its base. Some large boulders and rocks are found scattering near the base of this cliff and hitting houses there. When this depression is added to the affected area, the likelihood can increase as high as $35 \%$.

Furthermore, some thought is required about the presence of colluviums that are found accumulated thick particularly along gullies. These colluviums must have been wetter than those covering the other convex parts of the slope though the earthquake happened in the late dry season, thus having increased the risk of landslides.

To highlight this feature of slope terrain, "rain concentration (RC) values" (Nakata et al., 2017) are calculated for the entire stretch of the target area. The "RC" values are obtained by the following procedure:

1) The same DIPM is used to trace movements of rain particles, which are uniformly generated over the entire stretch of the target terrain. Parameters $n$, and $i_{d}$ for each rain particle are set at $0.05 \mathrm{~m}^{1 / 3} \mathrm{~s}$ and 0 degree, respectively.

2) Allowing all rain particles to be completely drained, we count the number of rain particles that pass through each cell of the terrain grid. This number for each cell is then divided by the initial number of rain particles in one cell and is defined as the "rain concentration (RC)."

To calculate RC values, the computational area should be larger than the DIPM computational area to allow rain particles within the whole catchment areas to flow through the DIPM computational area. Fig. 4 shows RC value distribution over the whole target area, $A_{0}$. The area with "RC" values larger than a threshold value of $r_{t}, A_{r c}\left(R C>r_{t}\right)$ is laid over the affected area in the DIPM simulation, $A_{s}$, and the following union of sets is thus considered herein:

$$
A_{u}\left(r_{t}\right)=A_{r c}\left(R C \geq r_{t}\right) \cap A_{s}
$$

Given this $A_{u}\left(r_{t}\right)$, the likelihood is redefined as:

$$
L\left(r_{t}\right)=\frac{A_{u}\left(r_{t}\right) \cap A_{a}}{A_{u}\left(r_{t}\right) \cup A_{a}}
$$

It turns out that $L\left(r_{t}\right)$ for the area $A_{1}$ reaches its maximum value of $47.3 \%$ when $r_{t}=50$ (Fig. 5). For the area $A_{2}$ excluding the old landslide trace, $L\left(r_{t}\right)$ reaches its maximum value of $37 \%$ when $r_{t}=63$. Including the old landslide trace, it goes up as high as $46 \%$.

\section{EXTRACTION OF UNSTABLE SOURCES}

$A_{u}(50)$ in Fig. 5 includes the source areas with $i_{f}=40^{\circ}$, main track and depositional cones. Extracting only source areas with $i_{f}=40^{\circ}$ and expanding the target area to the whole study area $A_{0}$, one obtains suspected source areas $S_{S}$ with high risk, which areas include (1) visible source areas $S_{v}$ exposed in the 2015 Gorkha Earthquake, (2) past landslide source areas $S_{p}$, and (3) currently intact but possibly remaining unstable soil/rock mass areas $S_{R}$ (Fig. 6).

Since a greater part of southeast and east valley walls are in shade, the discussion in view of prediction likelihood is made only over the valley walls in the sun. The positive predictive value for extracted source areas $S_{S}$ in the sun is $58.6 \%$, meaning it has covered $58.6 \%$ of the visible newest and past source areas $\left(S_{v} \cup S_{p}\right)$. The prediction likelihood for the past and present source areas is given by:

$$
L_{s}=\frac{\left(S_{v} \cup S_{p}\right) \cap S_{S}}{\left(S_{v} \cup S_{p}\right) \cup S_{S}}
$$

where, $L_{S}=31.5 \%$ for the valley walls in the Sun in area $A_{0}$.

It is noted that almost all seemingly intact but presumably unstable source areas are found near the existing old and new scars (Fig. 7). To estimate the total volume of debris remaining in this area, we need to know the average thickness of colluvium accumulated along gullies. The UAV-photo-based DSM showing the post-quake terrain along the Trishuli River (Area $A_{2}$ ) was first georeferenced, and then the pre-quake DSM is subtracted from it to see how deep the valley walls were scraped (Fig. 8).

The area used to examine the topographic change is shown with a solid-line polygon in Fig.8 (a). The volume of decrease and increase in the affected area were shown in Fig. 8 (b). The total volume loss is estimated to be about $8.7 \times 10^{6}$ $\mathrm{m}^{3}$ for the entire stretch of the source areas of total $0.76 \times 10^{6}$ $\mathrm{m}^{2}$. Assuming most of the volume decrease was due to the landslides along gullies, the average thickness of detached soil mass can be calculated to be about $11 \mathrm{~m}$. The total volume increases in the depositional areas of total $0.27 \times 10^{6} \mathrm{~m}^{2}$ was estimated to be about $2.1 \times 10^{6} \mathrm{~m}^{3}$, which is almost one fourth of the detached soil volume. This indicates that approximately three quarters of the soil mass deposited along the Trishuli River has been carried away downstream.

If the obtained average depth of $11 \mathrm{~m}$ for the steep gullies can be extrapolated for the whole valley walls in the sun within the entire study area of $A_{0}$, the total volume of potentially hidden unstable soil masses is estimated to be about $14 \times 10^{6} \mathrm{~m}^{3}$. This volume does not include the valley walls in shade. Making no distinction between those detached and remaining along gullies, total $1.3 \sim 107 \mathrm{~m}^{3}$ debris masses are considered to be still hidden in the shade. Therefore, we cannot keep our eyes off these slopes particularly where major roads cut into already un-stable slopes.

\section{CONCLUSIONS}

For the steep mountain slopes along the Trishuli River in the Himalaya, which was hit by the 2015 Gorkha Earthquake, 


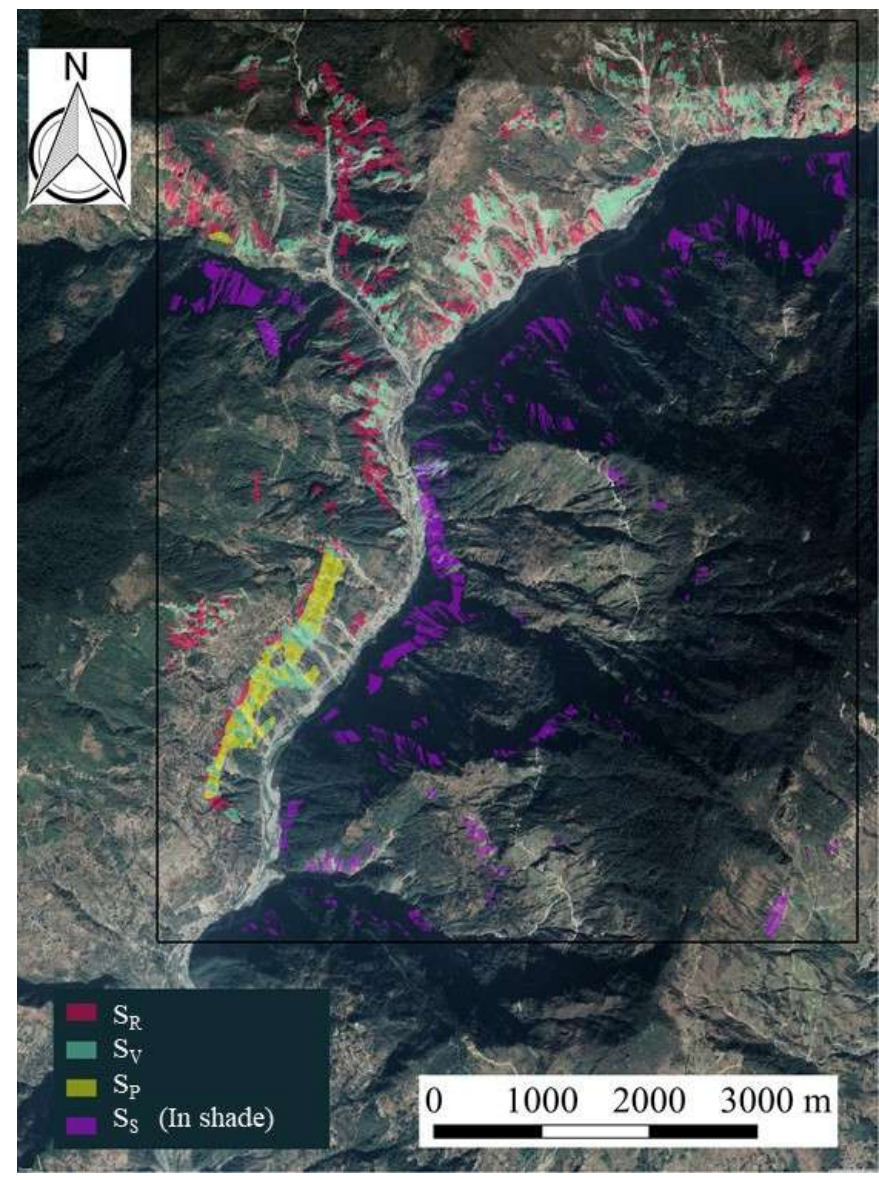

Fig. 6: Estimated source areas $S_{s}$ in the sun includeing (1) visible source areas $S_{v}$ exposed in the 2015 Gorkha Earthquake, (2) past landslide source areas $S_{p}$, and (3) currently intact but presumably remaining unstable soil/rock mass areas $S_{R}$ : Those estimated in the shade are shown as $S_{S}$ (In shade)

an attempt was made to numerically assess the remaining risk of slope failures in terms of three mechanical parameters, namely, the critical angle $i_{f}$ at which the debris mass start sliding, Gauckler-Manning roughness coefficient $n$, and angle of repose $i_{d}$ for the flowing debris mass. In a search for the optimum set of parameters, it turned out that the critical angle $i_{f}$ is less sensitive to the extent of the computational area though the other two parameters can vary drastically reflecting the interaction among debris masses flowing down into the deep valley of the Trishuli River. For the target ragged terrain, $i_{f}=$ $40^{0}$ seems to be the optimal value. More importantly, the presence of colluviums that are found to be thickly accumulated particularly along gullies is to be considered. These colluviums must have been wetter than those covering the other convex parts of the slope though the earthquake happened in the late dry season, thus having increased the risk of landslides. To highlight this feature of the terrain that easily collect running water, "rain concentration (RC) values" (Nakata et al., 2017) are calculated for the entire stretch of the target area. Positive

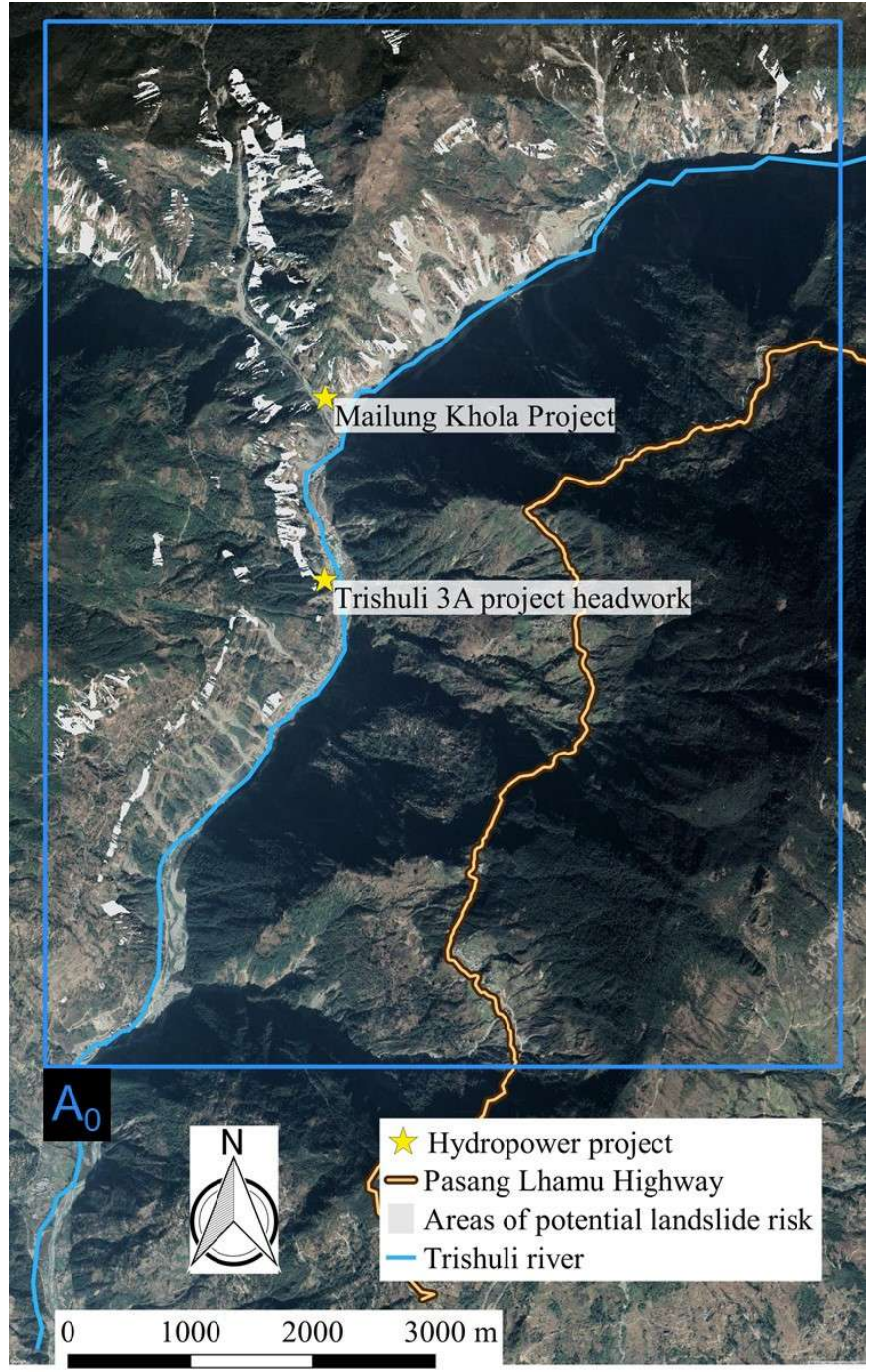

Fig. 7: Presumably remaining unstable soil/rock mass areas and infrastructures

predictive value for the estimated source areas, given by $i_{f}=$ $40^{\circ}$ and $\mathrm{RC}$ values greater than 50 , was $58.6 \%$. This means that $58.6 \%$ of the visible sources of debris mass $\left(S_{v} \cup S_{p}\right)$ in the sun were found within the estimated areas. It is noted that almost all seemingly intact but presumably unstable source areas $S_{R}$ are found near existing old and new scars. Assuming the average thickness is $11 \mathrm{~m}$ for the colluvium in $S_{R}$, the total volume of potentially hidden unstable soil masses is estimated to be about $14 \times 10^{7} \mathrm{~m}^{3}$. This volume does not include the opposite valley walls in shade. Making no distinction between those detached and remaining along gullies, total $1.3 \times 10^{7} \mathrm{~m}^{3}$ debris masses are considered to be still hidden in the shade. We are thus to be alert to the possible dangers particularly where we have important facilities.

\section{ACKNOWLEDGEMENTS}

The authors are indebted to the Japan Society for the Promotion of Science, who has provided the authors with a 


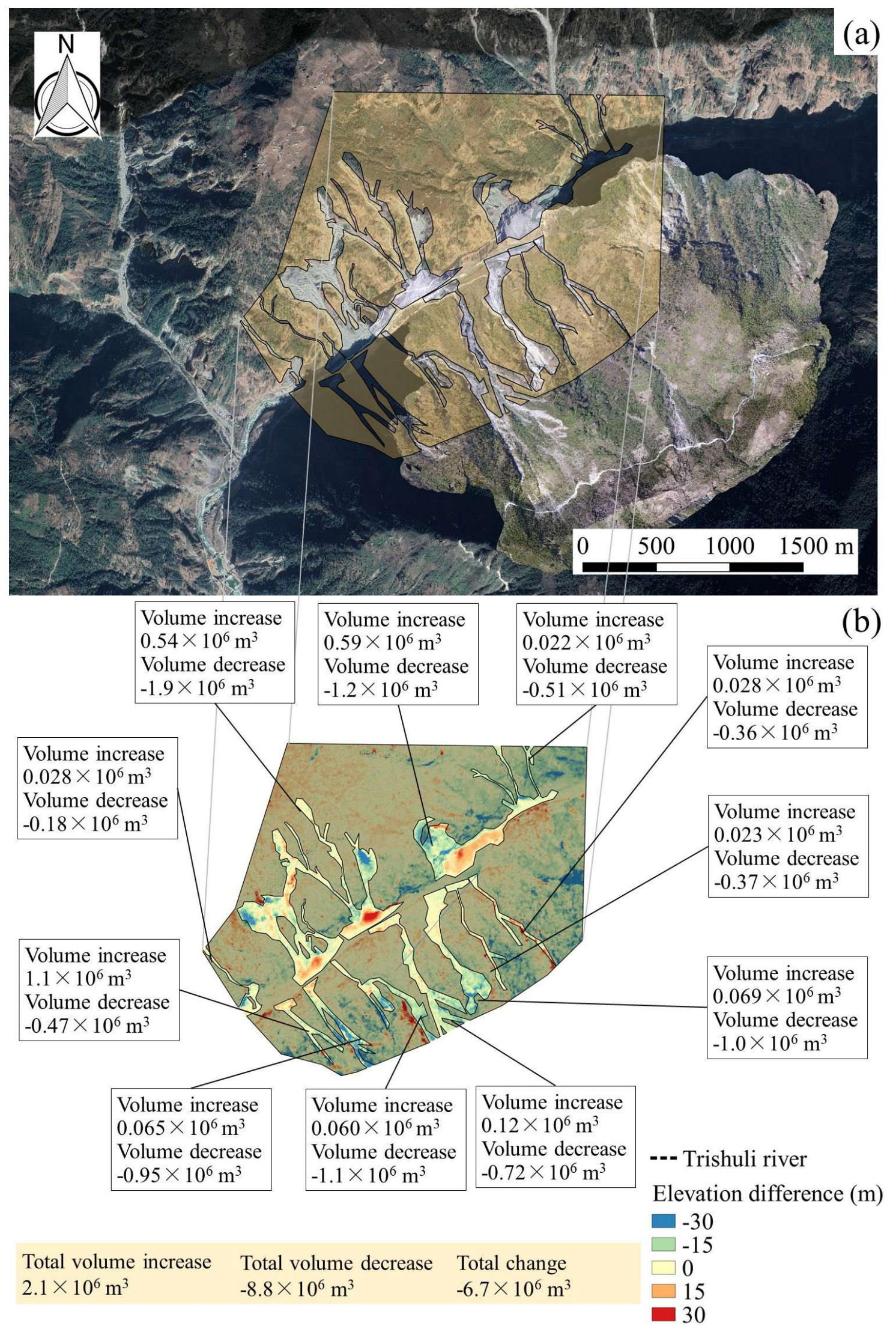

Fig. 8: (a) Affected areas extracted from both satellite images and UAV-based orthophoto (b) Volume change along each gully 
financial support for conducting field surveys in Nepal; the support is "Detection of earthquake-induced shallow and deepseated tectonic deformations and stresses and its implication to land conservation strategies," Grant-in-Aid for Scientific Research (A), No. 26249069 (Leader: Kazuo Konagai). Special thanks go to Mr. Masashi Ogawa, Ambassador, Mr. Shinya Machida, Counsellor, and Mr. Makoto Oyama, First Secretary at the Embassy of Japan, Kathmandu, Nepal, Prof. Dr. Tara Nidhi Bhattarai and Dr. Danda Pani Adhikari, Department of Geology, Tribhuvan University who have kindly provided the authors with important pieces of information regarding damage caused by the Gorkha Earthquake as well as every convenience for field surveys.

\section{REFERENCES}

Arai, H. and Tokimatsu, K., 2004, S-Wave Velocity Profiling by Inversion of Microtremor H/V Spectrum. Bulletin of the Seismological Society of America, v. 94, No.1, pp.53-63.

Dhital, M.R., 2015, Geology of Nepal Himalaya: Regional Perspective of the Classic Collided Orogen. Springer, $498 \mathrm{p}$.

Ghimire, T., Paudel, L. P., and Pant, B., 2007. The Devastating Ramche Landslide (Rasuwa) and the Future of Polchet Residents, Journal of Nepal Geological Society, v. 36, Special Issue, pp. 27.

Gnyawali, K. R. and Adhikari, B. R., 2017, Spatial relations of earthquake induced landslides triggered by 2015 Gorkha earthquake $\mathrm{Mw}=7.8$. Advancing culture of living with landslides, v. 4, pp. 85-93.
Government of Nepal National Planning Commission, 2015, Post Disaster Needs Assessment, v. B Sector Reports, pp. 141-153.

Konagai, K., Pokhrel, R. M., Ikeda, T., Shiga, M., Aftabur R.M., and Okuda, H., 2016, Follow-up report of damage caused by the Gorkha Earthquake, Nepal, of April 25th, 2015. JSCE Journal of Disaster Fact Sheets, FS2016-E-0002.

Nakamura, Y., 1989, A method for dynamic characteristics estimation of subsurface using microtremor on the ground surface. Quarterly Report of RTRI (Railway Technical Research Institute) (Japan), V. 30, pp.25-33.

Nakata, A.M. and Matsushima, T., 2014, Landslide Simulation Based on Particle Method: Toward Statistical Risk Evaluation. Computational Engineering and Science for Safety and Environmental Problems, pp. 1523-1528.

Nakata, A.M. and Matsushima, T., 2014, Statistical evaluation of damage area due to heavy-rain-induced landslide. Computer Methods and Recent Advances in Geomechanics (IACMAG), pp. 397-399.

Nakata, A.M., Tomita, H., Konagai, K., Matsushima, T., Shiga, M., Ikeda T., and Pokhrel, R.M., 2017, Analysis of landslides effects triggered by Gorkha Earthquake along Trishuli River, 2017, JSCE Symposium on Earthquake Engineering, C23, Oct. 12th, 2017.

Tadono, T., Ishida, H., Oda, F., Naito, S., Minakawa, K., and Iwamoto, H., 2014, Precise Global DEM Generation by ALOS PRISM. ISPRS Annals of the Photogrammetry, Remote Sensing and Spatial Information Sciences, v. 2(4), pp.71-76. 